\title{
CEsifo \\ WORKING

\section{Taxing Intellectual Property in the Global Economy: A Plea for Regulated and Internationally Coordinated Profit Splitting}

Wolfram F. Richter 


\section{Impressum:}

CESifo Working Papers

ISSN 2364-1428 (electronic version)

Publisher and distributor: Munich Society for the Promotion of Economic Research - CESifo $\mathrm{GmbH}$

The international platform of Ludwigs-Maximilians University's Center for Economic Studies and the ifo Institute

Poschingerstr. 5, 81679 Munich, Germany

Telephone +49 (o)89 2180-2740, Telefax +49 (o)89 2180-17845, email office@cesifo.de

Editors: Clemens Fuest, Oliver Falck, Jasmin Gröschl

www.cesifo-group.org/wp

An electronic version of the paper may be downloaded

- from the SSRN website: $\quad$ www.SSRN.com

- from the RePEc website: $\quad$ www.RePEc.org

- from the CESifo website: www.CESifo-group.org/wp 


\title{
Taxing Intellectual Property in the Global Economy: A Plea for Regulated and Internationally Coordinated Profit Splitting
}

\begin{abstract}
Inter-country equity in the taxation of IP is a contentious issue. With its BEPS initiative, the OECD aims at taxing in accordance with value creation even though there are admitted difficulties in determining the actual place of value creation. The European Commission promotes the introduction of unitary taxation. The proposal's drawback is that it lacks incentive compatibility in information exchange. Furthermore, it stipulates a cost-dependent apportionment of the common consolidated corporate tax base that incentivizes locating R\&D in low-tax countries. Against this background, this paper makes a case for an internationally regulated split of the profit earned with imported IP.
\end{abstract}

JEL-Codes: H250, O340, M480, F230.

Keywords: intellectual property, tax competition, profit split, formulary apportionment, Shapley value.

\author{
Wolfram F. Richter \\ TU Dortmund University \\ Department of Economics \\ Germany - 44221 Dortmund \\ Wolfram.Richter@tu-dortmund.de
}

May 2017

Valuable comments and suggestions made by Markus Breuer, Stefan Homburg, Dominika Langenmayr, Mohammed Mardan, Sören Bo Nielsen, Michael Perdue, Ulrich Schreiber, and Christoph Spengel on earlier versions of this paper are gratefully acknowledged. 


\section{Introduction}

Intellectual property (IP) and intangibles are of increasing importance for multinational enterprises (MNEs). The value of patents, trademarks, copyrights, and other intangible assets as a percentage of total market value for the largest US companies is estimated to have increased from 16.8\% in 1975 to almost 80\% in 2005 (Parr, 2013, citing Ocean Tomo). As a result, the adequate pricing of IP in transactions between the affiliates of multinationals has become a pressing issue for corporate management and even more so for tax authorities. It is a characteristic feature of IP that the application of the standard methods for the determination of arm's length transfer prices - the comparable uncontrolled-price method, the cost-plus method, and the resale-minus method - is, in most cases, arbitrary.

Companies, particularly those affiliated with the digital economy, take advantage of this situation. They are incentivized to shift profits to low-tax jurisdictions, thus, reducing tax payments (Commission Expert Group on Taxation of the Digital Economy, 2014). As a result, the connection between taxation and real economic activity threatens to get more and more lost. The OECD responded in 2013 by launching its action plan against base erosion and profit shifting (BEPS). The initiative seeks to better align taxation and transfer pricing outcomes with value creation, although the difficulty of determining the jurisdiction in which value is created in the digital economy is frankly acknowledged (OECD, 2013, p. 10).

Profit shifting is, by nature, difficult to measure. There is, however, evidence that IP plays a key role. According to estimates from Grubert (2003), income derived from R\&D-based intangibles accounts for about half of the income shifted from high-tax to low-tax countries. (Heckemeyer and Overesch (2013) even attribute as much as $72 \%$ of profit shifting to the pricing of IP in intra-firm transactions and to the strategic location of ownership rights.)

This paper is motivated by the presumption that the empirical findings are indications of a fundamental design flaw in the governing tax law. The design flaw is in not treating rival and non-rival production factors as separate sources of income, and it has two dimensions. One is that the returns to the rival input equity and the non-rival input know-how are jointly taxed and, hence, not separated. The other is the misconception that business profits can be separated from royalties paid to legally independent but economically affiliated companies. There is, however, no economic basis for separating the latter two types of income. According to Dunning (1979), the desire to exploit know-how is the primary motive for establishing an 
MNE. If this is correct, profit earned abroad and royalties received from abroad are both inseparable returns on the same investment; the governing tax law, however, ignores this.

In this paper a number of proposals for reforming the international taxation of MNEs are discussed and compared. An own one is presented which is special in that it places the taxation of know-how in the center. The most prominent proposals discussed in the literature are claimed to suffer from not doing so.

The proposal having received the most attention of late is the Destination-Based Cash Flow Tax (DBCFT) promoted by Auerbach and Devereux (2015). The clear advantage of this tax is that it secures allocational efficiency through a clever idea of effectively taxing lump-sum income. This advantage does not, however, come without a price. As I shall argue, the tax is vulnerable to tax competition, and it can be criticized for its lack of inter-country equity.

The European Commission (2011, 2015) promotes the introduction of unitary taxation and formulary apportionment (FA) in the European Union. The proposal - known as the Common Consolidated Corporate Tax Base (CCCTB) - stands out due to two positive features. One is inter-country equity in the division of the common tax base; the other is the effect it has on tax planning. The CCCTB removes the incentive for MNEs to engage in aggressive tax planning. Profits earned by a company's affiliates are consolidated before being taxed so that tax payments cannot be manipulated by pure profit shifting. I shall argue, however, that there are two equally clear disadvantages. One is a lack of incentive compatibility in information exchange between the participating countries, i.e., the tax authority of the country in which R\&D is pursued has an incentive to tolerate misreporting by its resident MNEs. The other disadvantage is the vulnerability to tax competition. According to the Commission's proposal, the share of the common tax base apportioned to a participating country depends on local activity measured by costs and sales. Income division based on cost, however, incentivizes MNEs to relocate R\&D in low-tax jurisdictions. Accordingly, high-tax countries with strong $R \& D$ activities have reason to reject such a policy regime.

The distortionary effect of unitary taxation on the location of production could easily be avoided by discarding costs in the weighting scheme used to apportion the common tax base. The resulting formula would then be sales-based as has, in fact, been suggested by Avi-Yonah (1993). I shall argue that the second disadvantage of unitary taxation, the lack of incentive compatibility in information exchange, cannot, however, be overcome by just resorting to a sales-based formula. 
Adhering to the governing tax law and limiting potential reforms to specific regulations, has also been considered. An example is Fuest et al. (2013) who propose the extension of source taxation and the imposition of creditable withholding taxes on interest and royalty. Another example is Desai and Dharmapala (2011) who recommend switching from the current twobook reporting system to a one-book system. MNEs should be required to report transfer prices which are consistent with those used internally. I shall argue that neither proposal is really convincing. The imposition of a withholding tax with limited crediting is unable to guarantee inter-country equity, while a one-book system sets incentives for costly centralization. Neither inter-country equity nor resilience against tax competition is guaranteed, as much depends on the parameter constellations.

This is the background against which the present paper makes a case for Regulated Profit Splitting (RPS). The term stands for an internationally agreed and regulated split of the profit earned with imported IP. MNEs are assumed to consider the splitting ratio to be exogenous. The exogeneity makes a difference to Boos (2003, p. 204) who discusses division rules based on hypothetical negotiations between independent parties. RPS is modeled after the Goldscheider 25\% Rule. In fact, Goldscheider has proposed that 25\% of the expected profit earned from products that incorporate certain IP be allocated to the licenser (Goldscheider, Jarosz, and Mulhern, 2005). A similar proposal has been made by Knoppe (1972). This paper does not propose a particular split. However, $50 \%$ is an appealing benchmark of equity considerations for the following reason. Taxable profit is only generated in the licensee's country when this country cooperates with the licenser's country. In this cooperation, the former provides earnings opportunities, while the latter provides know-how, which is a nonrival production input. As the marginal cost of provision is zero in both cases, an equal split of the tax base appears to be just and fair.

It seems that RPS has never received any thorough analysis in the theoretical literature, thus far. This is astonishing as RPS has merits in all of the mentioned policy dimensions. Incentive compatibility in information exchange is not an issue of concern under RPS. And by appropriate choice of the profit-splitting parameter, inter-country equity as well as resilience against tax competition can be secured.

The paper is structured as follows: Section 2 briefly summarizes the related literature. Section 3 establishes the model of an MNE and specifies the policy objectives. Section 4 investigates residence taxation in general and the DBCFT in particular. Section 5 analyzes unitary taxation and formulary apportionment. Section 6 identifies the deficiencies of the governing tax law 
with two sets of books. Section 7 examines the implications of switching to a one-book reporting system. Section 8 analyzes RPS. Section 9 adds some thoughts on implementation, and, finally, section 10 summarizes.

\section{Related literature}

There is a growing body of literature trying to estimate the extent of base erosion and profit shifting in corporate taxation. The estimates are subject to large uncertainty and have to be interpreted with great caution. Surveying the literature, Riedel (2014) estimates that MNEs transfer $5 \%$ to $30 \%$ of their earned income from high-tax to low-tax jurisdictions. For additional recent surveys see Dharmapala (2014) and the European Commission (2015). By its very nature, profit shifting is difficult to measure. There is not just one channel. Profit is not only shifted via strategic mispricing of intra-firm trade but also via corporate restructuring, the unbundling and migration of ownership rights, and the use of intra-firm debt. Synthesizing the evidence from 25 studies Heckemeyer et al. (2013) conclude that transfer pricing and licensing are the dominant profit-shifting channels. The recent literature therefore focuses increasingly on tax planning with IP (Grubert, 2003; Mutti et al., 2009; Dischinger et al., 2011; Karkinsky et al., 2012; Griffith, Miller, and O’Conell, 2014; Evers et al., 2014; Beer et al., 2015; Evers et al., 2015; Bräutigam et al., 2015; Alstadsaeter et al., 2015; Dudar et al., 2015).

The effect of taxation on profit-shifting activity is documented by this kind of research. The normative question of policy design is not at focus. It is mooted by Fuest and co-authors (2013). These researchers raise the question of how they would like international corporate taxation to work, and they discuss the pros and cons of four policy options: (i) enforcing residence taxation for which they, however, see little chance of being adopted internationally, (ii) extending source taxation, which they deem to be more promising, (iii) reforming corporate taxation fundamentally by introducing the CCCTB or by switching to a destinationbased cash-flow tax which they consider to be interesting options only for the longer perspective, and (iv) enforcing stricter reporting and transparency requirements of which they do not expect much improvement. In the short run, Fuest et al. (2013) recommend extending source taxation and imposing creditable withholding taxes on interest and royalty payments.

Desai et al. (2011) propose countering base erosion and profit shifting by reforming the determination of transfer prices. More precisely, they propose switching from a two-book to a 
one-book reporting system. A one-book system is appealing in that it sustains global production efficiency when transfer prices are uncontrolled.

The potential merits of decoupling, i.e., the use of different transfer prices for internal and external statements, is investigated in a number of papers. An example is Johnson (2006) who sets up a sequential model in which two related legal entities (profit centers) trade IP. One firm invests in $R \& D$, thus producing a certain output of IP which is sold to the second firm in a next step. Johnson shows that decoupling can boost the overall group profit. Johnson's sequential setting is picked up by Hiemann and Reichelstein (2012). These authors confirm the merits of decoupling. It allows MNEs to make better investments and to also earn higher after-tax profits. The effects of decoupling are also analyzed by Nielsen (2014). He presents a model with an MNE delegating its quantity-setting power to a subsidiary which is engaged in Cournot-Nash competition with an uncontrolled second supplier. In this framework, he works out the trade-offs that a ban on decoupling - as well as other constraints on the choice of transfer prices - has for corporate behavior. However, his analysis does not result in a clear assessment.

Starting with McLure (1980), a sizable literature has developed around the idea of consolidating tax bases and applying FA. The European Commission (2011) has taken up this idea and proposed an optional CССТВ for Europe. In the relaunched version of 2015, the Commission advances the view that all MNEs with global revenues exceeding a certain threshold should be taxed on the basis of a compulsory CCСТВ. For a discussion of CCCTB see Devereux (2004), Fuest (2008), and Altshuler et al. (2010). Avi-Yonah (1993) suggests using sales as the sole factor of FA. Avi-Yonah et al. (2009) and Luckhaupt et al. (2012) recommend an apportionment method that combines a fixed standard profit margin with a sales-based apportionment of residual profit.

FA can be interpreted as the attempt to equitably divide an MNE's profit between its affiliates. There are proposals in the literature which share this objective but draw different conclusions. Gonnet et al. (2007) and Vögele et al. (2008) apply game-theoretic concepts, and they propose the use of Shapley's value. As is shown in the next section, the Shapley theory supports dividing the profit earned from licensed know-how between the licenser and licensee.

The most revolutionary reform proposal thus far is made by Auerbach and Devereux (2015). These authors promote a switch from the traditional system of capital income taxation to a 
destination-based cash flow tax (DBCFT). The proposal is targeted at allocational efficiency. See also Auerbach et al. (2017).

\section{Know-how, intellectual property, and the model of a multinational enterprise}

Know-how, $K$, is assumed to be the single variable input of production. It is the result of $\mathrm{R} \& \mathrm{D}$. The country in which know-how is developed is called the home country, and the country only sharing the use of know-how is called the host country. In what follows no differentiation is made between R\&D and (the development of) know-how. Differentiation, however, is made between know-how and intellectual property for two reasons. The first one is to account for the difficulty to exclude third parties from using know-how without paying for it. R\&D activities produce local spillover effects, $E(K)$, on which property rights cannot be acquired. Still, spillovers effectively increase the home country's tax base. The second reason for differentiating between know-how and intellectual property is to enable the study of unbundled ownership rights. Contracted research often has the effect that the country in which patents are held is not the same country in which $\mathrm{R} \& \mathrm{D}$ is undertaken. Let $C(K)$ capture the cost of R\&D, which is assumed to be increasing and weakly convex: $C^{\prime}>0, C^{\prime \prime} \geq 0$.

The focus is on an MNE earning profit at home and abroad. $F=F(K)$ and $f=f(K)$ are the (expected) profit contributions to be earned at home and abroad, respectively. The derivatives, $F^{\prime}, f^{\prime}$, and $E^{\prime}$, are positive and decreasing in $K$. The analysis does not rely on explicitly differentiating between expected and realized profits. Such differentiation could be made explicit by setting $F(K)=p(K) \Phi(K), f(K)=p(K) \varphi(K)$, with $\Phi, \varphi$ denoting realized profit contributions and $p(K)$ denoting the probability of successful R\&D. One would think that $p(K)$ increases in $K$ while the realized profit contributions need not do so. A plausible example for constancy would be the one in which innovation is of the zero-one type.

At the country level, MNE is represented by divisions. Since know-how is developed in the home country, the division associated with $F$ is called the developing division. The division located in the host country and associated with $f$ is called the sharing division, as the host country is sharing the use of developed know-how. $R_{i}(K)$ is the royalty which the sharing division has to pay internally. Profit is taxed at rate $t$ in the host country and at rate $T$ in the home country. In what follows, the focus is on the scenario characterized by $T>t$. This is so for the following two reasons: Countries with strong $R \& D$ activity tend to be high-tax countries (Dudar et al., 2015); and, tax competition for R\&D is non-trivial when home is a 
high-tax country. Let the host country's tax base be denoted by $b$ and the home country's tax base by $B$. Profits after tax are

$$
\pi(K) \equiv f(K)-R_{i}(K)-t b(K) \text { and } \Pi(K) \equiv F(K)-C(K)+R_{i}(K)-T B(K)
$$

The MNE is assumed to maximize $\pi+\Pi$. The definitions in eq. (1) capture the main features of international corporate taxation. Corporate income is taxed at source and exempted from taxation in the parent's country of residence. If the latter country should apply a system of crediting, special provisions typically allow the MNE to postpone the taxation of repatriated profits. In a simple model, the difference to effective exemption can be ignored.

\subsection{Policy objectives}

This paper studies the advantages and disadvantages of various proposals that have been made to reform the international order of corporate income taxation. From a welfare theoretic point of view, global efficiency should certainly be the ultimate standard of evaluation. One has to bear in mind, however, that potential reforms have to be negotiated by governments that rank national interest higher than global efficiency. A specific reform proposal is, therefore, feasible only when the national interest of all participating countries is respected.

The precise meaning of national interest will be detailed in subsequent sections. Three specific manifestations will be considered. The first one is called inter-country equity. It requires taxable income, $f+F+E-C$, to be fairly divided between home and host; for details see subsection 3.2. The second manifestation relates to the home country. A country hosting R\&D activities will take care not to lose them to foreign countries. This is best rationalized by assuming that both, $F-C$ and $E$, are positive and potentially large as seems to be a characteristic feature of the digital economy. The home country may therefore be expected to oppose any international tax reform that threatens its ability to host R\&D. Such threats exist if the hosting of $R \& D$ is responsive to low tax rates. As the choice of tax rates would hardly be part of an international tax agreement, the hosting of R\&D is best sheltered against tax competition by a regime in which high tax rates are conducive for hosting. In other words, the hosting of $R \& D$ should be resilient against a foreign low-tax policy. Let us call this desideratum resilience against tax competition. The third manifestation of the national interest relates to the host country. If its tax base, $b$, is made dependent on information collected in home, host has to rely on truthful reporting; tax auditing in home by host will not be an 
option. Truthful reporting is threatened if home's government and the MNE have concurrent interests in transmitting the information needed for tax assessment; rather, they should have opposing interests. Let us call this desideratum incentive compatibility in information exchange.

As mentioned, global efficiency should be the ultimate objective for evaluating tax regimes. The following analysis follows this objective by focusing on global production efficiency. Two specific manifestations are differentiated. The quantity $K_{i}^{*}$ is called (globally) internally (production) efficient if the sum of marginal profit contributions equals marginal cost: $F^{\prime}+f^{\prime}=C^{\prime}$. This is Samuelson's rule. Internal efficiency refers to the inside of the MNE. By contrast, external efficiency includes non-patentable spillover effects generated by $R \& D$. The quantity $K_{e}^{*}$ is called (globally) externally efficient if $F^{\prime}+f^{\prime}+E^{\prime}=C^{\prime}$. Another possible reason for differentiating between internal and external efficiency could be market power caused by the monopolization of IP. In this paper, the differentiation is, however, justified referring to non-patentable spillover effects. The reason is that these are more strongly connected with the home country. It is only plausible to assume that external benefits, $E(K)$, are primarily local in the sense that they accrue to the country in which $R \& D$ is pursued. By contrast, the inefficiency of monopolization tends to spread over all countries in which the MNE is active.

\subsection{Inter-country equity}

The issue of inter-country (tax) equity is raised when countries have to cooperate for generating taxable income. In the present model, home provides know-how and host provides market opportunities. As the use of know-how is non-rival, both provisions are without cost and, in this sense, comparable. Such a constellation raises the question of an equitable division of the taxable income earned by the MNE's operations in the host country. Host's tax base $b$ should be larger than zero, since the country provides the opportunity to extend the MNE's operations. On the other hand, $b$ should be less than $f(K)$, because the know-how comes from outside. An equal split with $b=f / 2$ is a natural benchmark of inter-country equity. Applying the Shapley value of cooperative game theory strengthens this suggestion. However, reasoning in the manner of Shapley also provides an argument against an equal split, as is shown next. 
A cooperative game consists of a set of players and a characteristic function specifying for each subset of players the value $v$ these players are able to create by concerted action. In the present context, the countries take the role of the players and taxable income takes the role of value. On a stand-alone basis, the value created by home is $v$ (home) $\equiv F(\bar{K})+E(\bar{K})-$ $C(\bar{K})=\max [F(K)+E(K)-C(K)]$ and the value of host is $v$ (host) $\equiv 0$. If the countries cooperate, their joint value is $v$ (home,host $) \equiv F\left(K_{e}^{*}\right)+E\left(K_{e}^{*}\right)-C\left(K_{e}^{*}\right)+f\left(K_{e}^{*}\right)=$ $\max [F+E-C+f]$. The structure of the game is reminiscent of the one discussed by Shapley (1967) under the heading "the landlord and the peasants”. Just as a peasant can only create value from farming when he cooperates with the landlord, the host country can only create value from using licensed know-how when cooperating with the country wherein said know-how has been developed. Shapley's proposal is to divide the value of the grand coalition among the players according to the average marginal value each player contributes when joining the grand coalition in a random order. When applied to host, this implies the following: with a probability of one half, host joins the grand coalition before home does; the marginal contribution is zero in this case. With an equal probability of one half, host joins the grand coalition after home and its marginal contribution is $v$ (home,host) $-v$ (home). Following Shapley, taxable income allocated to host should, therefore, be

$$
\begin{aligned}
& b \equiv \frac{1}{2}\left[\left(F\left(K_{e}^{*}\right)+E\left(K_{e}^{*}\right)-C\left(K_{e}^{*}\right)+f\left(K_{e}^{*}\right)\right)-(F(\bar{K})+E(\bar{K})-C(\bar{K}))\right] \\
& =\frac{1}{2}\left[f\left(K_{e}^{*}\right)+\frac{1}{2}\left(K_{e}^{*}-\bar{K}\right)^{2}\left(F^{\prime \prime}+E^{\prime \prime}-C^{\prime}\right)\right] \leq \frac{1}{2} f\left(K_{e}^{*}\right)
\end{aligned}
$$

If the second-order term in eq. (2) can be ignored, the Shapley value provides support for the equal-split solution. The taxable income generated in host is shared with home while the taxable income generated in home is not shared. This results because home generates taxable income even when not cooperating.

In general, the second-order term in eq. (2) cannot, however, be ignored. It can only be ignored if $K_{e}^{*}$ is close to $\bar{K}$ or if $F^{\prime \prime}+E^{\prime \prime}-C^{\prime \prime}$ is close to zero. The former case results when host has relatively small weight in the MNE's global operations. The other case is obtained when home's value function is close to being linear. The second-order term can be interpreted as an external effect exerted on home's taxable income when the MNE increases its R\&D activity in order to match extended operations abroad. The Shapley value suggests the need to compensate for the suffered externality. In practice, however, it will be difficult to quantify the externality. This is why the following proposition emphasizes the upper bound of host's 
tax base. (This and further results are stated in the form of propositions with no particular claim to originality. I only use the form of propositions to make the discussion of reform options more transparent.)

Proposition 1: Inter-country equity requires dividing the taxable income, $f$, generated by the MNE's operations in the host country. The Shapley value suggests that host's tax base $b$ is positive but not larger than $f / 2$.

The idea of using Shapley's value for determining the transfer price of IP goes back to Gonnet et al. (2007) and Vögele et al. (2008). These authors do not, however, derive specific implications although some noteworthy ones exist. A first is that Proposition 1 can be easily extended to include multiple host countries. A second one applies when each of $n$ countries provides a non-rival input which is needed to produce the output $f$ in just one host country. In such a scenario, the Shapley approach suggests that the host country's tax base $b_{n}$ should be positive but not larger than $f /(n+1)$. This is because value is created in host only if when this country is the last to join the grand coalition, and the probability of this taking place equals $1 /(n+1)$. With regard to the discussion of formula apportionment in Section 5 , it is noteworthy to mention that the stated boundaries of $b_{n}$ are totally independent of the costs incurred by developing the various non-rival inputs. Let us speak of an equitable division of taxable income whenever $0<b_{n}<f$ is secured and let us differentiate this notion from the stronger one suggested by the Shapley value.

\section{Residence taxation}

Residence taxation can be modeled by setting $B \equiv f(K)+F(K)-C(K), b \equiv 0$. In such a regime, all income generated by an MNE is taxed in home as are spillover effect, $E(K)$. Residence taxation has certain advantages. An obvious one is that an MNE's maximization of profit, $\pi+\Pi=f(K)+F(K)-C(K)-T B$, sustains internal efficiency. As pure profit is effortless income, residence taxation can even be expected to enhance individual equity. The caveat is an empirical one. The production of know-how is not uniformly distributed throughout the world. On the contrary, spillovers bring about regional concentrations of 
innovation. The digital economy stands out as a prominent example. Regional concentration fosters growth and is therefore beneficial for the whole world. For the same reason, residence taxation can hardly be reconciled with inter-country equity. Host countries would have to forego their fair share of the taxable income earned in their own economies.

One might think that the DBCFT is a tax better accorded to inter-country equity. After all, sales are taxed - by definition - on a destination basis. The suggested conclusion that host collects positive revenue from taxing $f$ is, however, misleading. Two arguments make this clear. First, the DBCFT is effectively a tax on economic rent which explains its beneficial effects for efficiency (Auerbach and Devereux, 2015). As $f$ depends on the choice of $K$, it is not rent income, and, therefore, home's effective tax base cannot equal $f$. Secondly, the misleading conclusion is nothing but a fallacy of partial analysis. A full equilibrium analysis would make it clear that each country has to respect a balanced trade constraint. Hence, home has to pay with exports when importing $f$. The DBCFT however requires subsidizing labor costs, in general, and the labor costs entering exports, in particular. As a result, home does not collect any revenue from taxing profit accruing to foreign residents. It only collects revenue from taxing the lump-sum income of its own residents.

Let us mention in passing that residence taxation would satisfy incentive compatibility in information exchange if implemented as a DBCFT. It would, however, fail to be resilient against tax competition. An innovator clearly prefers a low profit-tax rate when choosing residence for planned $R \& D$.

Proposition 2: Like residence taxation, the DBCFT sustains internal efficiency. However, inter-country equity and resilience against tax competition are not secured

\section{Unitary taxation with formulary apportionment}

The European Commission (2011, 2015) promotes the introduction of a Common Consolidated Corporate Tax Base (CССТВ) as a prerequisite for the unitary taxation of large MNEs. In the simple model of the present paper, the consolidated base equals the sum of profit contributions: $B^{c} \equiv f(K)+F(K)-C(K)$. This base has to be divided between home and host so that each jurisdiction can apply its own tax rate to its apportioned share. Let $\lambda$ 
denote host's share. The tax base of home and host are then $B \equiv(1-\lambda) B^{c}$ and $b \equiv \lambda B^{c}$, respectively. The focus is on two prominent forms of formulary apportionment (FA).

One is the so-called Massachusetts formula favored by the Commission. Under this formula, local activity is measured by labor, capital (assets), and sales; all three factors enter the formula with equal weight. As the present model does not differentiate between labor and capital or between sales and profit contributions, it is suggestive to illustrate the Massachusetts formula by assigning a weight of $2 / 3$ to costs and a weight of $1 / 3$ to profit contributions:

$$
\lambda=\lambda_{M} \equiv \frac{1}{3} \frac{f}{f+F}, 1-\lambda_{M}=\frac{2}{3}+\frac{1}{3} \frac{F}{f+F} .
$$

The other prominent formula is called sales-based and has first been proposed by Avi-Yonah (1993). It uses sales as the sole factor and can be modeled by setting

$$
\lambda=\lambda_{S} \equiv \frac{f}{f+F}, 1-\lambda_{S}=\frac{F}{f+F}
$$

Unitary taxation has the appealing feature that no tax advantage is derived from shifting profit to a low-tax country. Provided $\lambda$ remains constant, the MNE's tax bill does not change. Unitary taxation is also appealing with regard to inter-country equity. If the Massachusetts formula is applied, the consolidated tax base will be equitably divided, in line with Shapley, as follows from $0<b=\lambda_{M} B^{c}=\frac{1}{3} f-\frac{1}{3} \frac{f}{f+F} C<f / 2$. If sales-based FA is applied, intercountry equity is secured in the weak sense: $0<b \equiv \lambda_{S} B^{c}=f-\frac{f}{f+F} C<f$. The Shapley condition, $b \leq f / 2$, only holds if the (expected) investment rate of return, $\rho \equiv(f+F-$ $C) / C$ does not exceed one hundred percent.

As has been widely discussed in the literature, FA suffers from setting a distortionary incentive for the international allocation of production factors (inter alia, McLure, 1980; Eggert et al., 2003; Wellisch, 2004; Pethig et al., 2007; Eichner et al., 2008; Gresik, 2010). Two kinds of distortions have to be considered. The first one results when the splitting parameter fails to be constant. This can be easily seen when studying the MNE's optimal choice of R\&D. The first-order condition is

$$
(1-\tau)\left[f^{\prime}+F^{\prime}-C^{\prime}\right]=-(T-t) \frac{d \lambda}{d K} B^{c}
$$


with $\tau \equiv \lambda t+(1-\lambda) T$ denoting the weighted average tax rate. Obviously, internal efficiency only holds if $\lambda$ is constant in $K$. In the present model, such constancy holds when the elasticities of $f$ and $F$ are equal. If $\lambda$ is not constant in $K$, little can be said about the efficiency effect of unitary taxation; rather, it is dependent on the sign of the right-hand side of eq. (5). The second kind of distortion results when the splitting parameter associated with home is cost dependent. In this case, MNEs are incentivized to react less by some marginal shifting of $R \& D$. Rather, they choose to relocate complete $R \& D$ activities. For the Massachusetts formula the incentive to relocate can be measured by the resulting decrease, $\Delta$, in the MNE's aggregate tax payment. Subtracting the tax to be paid when relocating from the tax to be paid when not relocating, yields $\Delta=\frac{2}{3}(T-t)(f+F-C)$. Obviously, the incentive increases with the tax gap and the MNE's aggregate profit. The big advantage of the salesbased formula is that it does not establish an incentive for relocating R\&D activities. Hence, sales-based FA is resilient against tax competition for R\&D, while the Massachusetts Formula is not. ${ }^{2}$

An additional critical feature plaguing unitary taxation is that countries would have to rely on truthful information exchange which cannot be taken for granted. The problem is easily shown for the scenario characterized by some constant $\lambda>0$. Let $\gamma$ be a parameter measuring the accuracy of reported costs. $\gamma=1$ stands for truthful reporting and $\gamma \neq 1$ for misreporting. Since

$$
\pi+\Pi=f+F-C-\tau B^{c}(\gamma), B^{c}(\gamma) \equiv(f+F-\gamma C)
$$

increases in $\gamma$, the MNE has an obvious incentive to over-report costs and to choose $\gamma>1$. The government of home will tolerate some marginal over-reporting if $t>0$ and if its objective function equals the sum of own tax revenue and the MNE's net profit. More precisely, one obtains $\frac{d}{d \gamma}\left[(1-\lambda) T B^{c}(\gamma)+\pi+\Pi\right]=t \lambda C>0$ at $\gamma=1$, assuming that $K=K(\gamma)$ solves the first-order condition associated with the maximization of (6). Obviously, unitary taxation gives home an incentive to pursue a beggar-thy-neighbor policy by tolerating misreporting of its resident MNEs. Thus, unitary taxation cannot guarantee incentive compatibility in information exchange. Let us summarize the main findings.

\footnotetext{
${ }^{2}$ In its most recent statements, the European Commission proposed combining the Massachusetts formula with a super-deduction for R\&D costs (http://europa.eu/rapid/press-release_IP-16-3471_en.htm). A harmonized superdeduction granted for costs will certainly increase the incentive to invest in $R \& D$ in each of the participating countries. It will not, however, remove the incentive to locate R\&D in low-tax countries.
} 
Proposition 3: Unitary taxation eliminates the incentive for profit shifting. The effect on allocational efficiency is case dependent. The big problem of unitary taxation is that it does not guarantee incentive compatibility in information exchange. Aside from that, the Massachusetts formula secures inter-country equity in the manner of Shapley, while the salesbased FA does so only if the (expected) investment rate of return does not exceed one hundred percent. Vice versa, sales-based FA secures resilience against tax competition for $\mathrm{R} \& \mathrm{D}$, while the Massachusetts formula does not.

\section{The governing tax law}

The governing tax law recognizes royalties paid by the licensee to the licenser of IP. It even accepts decoupling which means that the payment used internally for financial statements may differ from the payment used externally for tax reporting ("two books"). If $R_{i}(K)$ denotes the royalty which the sharing division has to pay internally, let $R_{e}(K)$ denote the one used for tax reporting.

\subsection{The case of bundled ownership rights}

Let us speak of bundled ownership rights if the developing division is the licenser of IP. In this case, the MNE will maximize aggregate profit,

$$
\pi+\Pi=(f+F-C)-t\left[f-R_{e}\right]-T\left[F+R_{e}-C\right]
$$

in $K$ and $R_{e} \in\left[\underline{R}_{e}, \bar{R}_{e}\right]$, where $\underline{R}_{e}, \bar{R}_{e}$ denote the bounds of transfer prices fixed by tax authorities. The internal transfer price, $R_{i}(K)$, cancels out when adding up profit contributions; it is not relevant for tax planning.

Assuming $T>t$, aggregate profit decreases in the reported transfer price. It therefore pays for the MNE to set $R_{e}$ as low as possible. This is done without any drawbacks, as external transfer prices have no managerial function. The only negative effect is imposed on the tax revenue of home. This will give its tax authority reason to negotiate over the choice of specific prices. In practice, its position is, however, weak because information about the 
productivity of know-how is typically not available. The informational asymmetry gives the MNE's headquarter a lot of leeway in setting $R_{e}$. For the sake of simplicity, let us assume that negative choices for $R_{e}$ are ruled out; negative transfer prices would certainly be challenged by the tax authority of home. Hence, let us set $\underline{R}_{e} \equiv 0$. The MNE's optimal choice then is $R_{e}=0$, and the taxes paid to home and host are $G=T[F-C]$ and $g=t f$, respectively. It is as if the returns to IP were taxed at source. This has positive and negative implications.

An advantage is that taxes paid do not rely on information collected in a foreign jurisdiction. Incentive compatibility in information exchange, therefore, is given. There are even positive efficiency effects. Maximizing eq. (7) with $R_{e} \equiv 0$ yields

$$
(1-T)\left[f^{\prime}+F^{\prime}-C^{\prime}\right]=-(T-t) f^{\prime}
$$

The last term on the right-hand side of eq. (8) works like a subsidy to R\&D. Such a subsidy is internally inefficient but it may raise external efficiency. The development of know-how exceeds the internally efficient level when some returns are taxed at a lower rate than the rate at which costs are deducted. However, external efficiency cannot be guaranteed. As there is no connection between $(T-t) f^{\prime}$ and $E^{\prime}$, the subsidy may well be too weak or too strong. The subsidy fails to target external efficiency.

There are, however, drawbacks. Taxing the returns at source cannot be reconciled with intercountry equity. It is not equitable that home has no share in the tax base generated in host. Of even greater concern is that the scenario characterized by $T>t$ and bundled ownership rights is not resilient against tax competition. The tax authority of home has to face the risk that its resident MNEs react by either unbundling ownership rights or by shifting $R \& D$ to host.

Proposition 4: Given that ownership rights are bundled and that $T>t$, the governing tax law will have the following effects:

(i) Profit contributions are effectively taxed at source which is not compatible with inter-country equity.

(ii) The tax gap works like an efficiency enhancing untargeted subsidy to R\&D.

(iii) Informational incentive compatibility is secured but resilience against tax competition is not. 


\subsection{Unbundling with exit taxation}

It is a widespread practice of MNEs to locate R\&D in a high-tax country and to then shift the ownership rights and received royalty payments to a low-tax country (Mutti et al., 2009). Such a strategy of unbundling is appealing, as it promises the MNE a "double dip" tax deduction. Not only are the costs of R\&D tax deductible in the home country, the royalties which home has to pay to host for the right of exploiting the know-how are equally deductible from home's tax base. Countries hosting $R \& D$ are incentivized to react by levying an exit tax on the international migration of IP. For a discussion see Russo (2007, 180-182) or Endres et al. (2015, §16.04).

To analyze unbundling, the focus is on the following extreme scenario. Ownership rights are successfully shifted to host, an exit tax, $X$, is levied by home and one hundred percent of the profit contribution earned by the developing division is taxed by host. The latter is achieved when the tax authority of home recognizes royalties in the amount of $R_{e} \equiv F-C$ paid by the developing division to the sharing division and when the former acts as a licensee and the latter as a licenser. As $T>t$ holds by assumption, it pays for the MNE to set $R_{e}$ as high as possible. The MNE would even set $R_{e}$ above $F-C$ if home allowed the MNE to offset the resulting loss against other income taxed by home. As there is no uncertainty in the model, home's tax authority can, however, be expected to reject this possibility and to enforce the noloss constraint, $R_{e} \leq F-C \equiv \bar{R}_{e}$. Note that the possibility of a cross-border loss offset does not change the picture. ${ }^{3}$ If host allows offsetting, the loss is offset against royalty revenue so that the sum of $F-C-R_{e}$ and $R_{e}$ is constant in $R_{e}$.

This is clearly an extreme scenario. If home demands a fairer share in the MNE's tax base, the governing tax law suggests levying a withholding tax, $w$, on royalty payments. Assuming $w$ to be creditable, home collects tax revenue in the amount of $G=w(F-C)+X$ while host collects $g=t f+(t-w)(F-C)$. A creditable withholding tax redistributes tax revenue between host and home. However, as crediting will be limited in practice, $w \leq t$, intercountry equity is out of reach.

A creditable withholding tax does not affect the MNE's optimization. Assuming unbundling and $R_{e} \equiv F-C$, aggregate profit after tax is

$$
\pi+\Pi=(1-t)[f+F-C]-X
$$

${ }^{3}$ Cross-border loss compensation for MNEs has become a major policy issue in Europe. For a discussion of the implications for tax compensation see Haufler and Mardan (2014). 
In its archetypical form, the exit tax $X$ equals the tax $T[F-C]$ that would have to be paid in home if IP were not migrated. Whenever $t$ is positive, such $X$ exceeds the benefit from unbundling, $\Delta \equiv(T-t)(F-C)$, and migration does not pay. In other words, when migration is observed, $X<\Delta$ must hold. The exit tax is ineffective in this case which may have two causes, one being informational asymmetry. The return to know-how lags behind costs incurred; therefore, expected profit can hardly serve as the base for a realistic exit tax. A realistic exit tax aims at withholding the tax advantage enjoyed by deducting the cost of $R \& D$, which can be modeled by setting $X \equiv x T C$. When expected sales are high and incurred costs are low, $X<\Delta$ results. The other potential cause for an ineffective exit tax is deliberate policy. As will be argued in the next subsection, home's tax authority may tolerate unbundling with the intention of preventing MNEs from moving R\&D to a low-tax host country. Maximizing eq. (9) yields

$$
(1-t)\left[f^{\prime}+F^{\prime}-C^{\prime}\right]=X^{\prime}
$$

When $X^{\prime}$ is positive, exit taxation has the effect of a tax on $\mathrm{R} \& \mathrm{D}$. Note that $X^{\prime}>0$ holds for $X \equiv x T C$.

Proposition 5: If an MNE chooses unbundling, the following holds:

(i) Exit taxation is ineffective, $X<\Delta=(T-t)(F-C)$.

(ii) If exit taxation is targeted at withholding the tax advantage enjoyed by deducting the cost of R\&D, it reduces internal efficiency.

(iii) Inter-country equity is not secured, not even by a withholding tax with limited crediting.

\subsection{Policy options under the governing tax law}

When the MNE chooses to unbundle, home suffers a loss of tax revenue. This holds even if a withholding tax with limited crediting is levied. The revenue collected from unbundling, is lower than the revenue collected from bundling:

$$
\begin{aligned}
G_{\text {unbund }} & =w[F-C]+X<(w+T-t)[F-C] \\
& =(T-(t-w))[F-C] \leq T[F-C]=G_{\text {bund }}
\end{aligned}
$$


The worst-case, however, is one in which the MNE chooses to move R\&D to a low-tax country. In the present model, this is less so due to losses in tax revenue but, rather, because of losses in spillover effects, $E$; the latter are assumed to be sizable. By contrast, losses in tax revenue need not be that large. Assuming that the MNE only optimizes transfer prices and respects the no-loss constraint, locating $\mathrm{R} \& \mathrm{D}$ in host implies $R_{e}=F, G=w F$, and $g=$ $t[f-C]+(t-w) F$. The tax revenue from relocating, $w F$, may well exceed the revenue collected, $T[F-C]$, if $\mathrm{R} \& \mathrm{D}$ remains located in home and if ownership rights remain bundled. The result of the comparison depends on the chosen functions and parameters.

If spillover effects are sizable, the tax authority of home will treat relocating of $R \& D$ as a worst case. The taxes the MNE would have to pay in case of relocating are MNE's outside option subjecting home's tax policy to a participation constraint:

$$
g+G \leq t[f+F-C]=(g+G)_{\text {reloc }}
$$

This reasoning suggests that negotiations of international tax law should be directed towards relaxing constraint (12). Note that this policy objective is in the interest of all countries. No country can gain from a tax regime that provides a locational advantage to the country choosing the lowest tax rate. Tax competition would end up in a kind of Bertrand equilibrium with zero tax rates.

If relaxing the participation constraint (12) were an accepted policy objective, this would have some far-reaching implications. The first one being that relying on withholding taxes would not help. They cancel out in eq. (12). Secondly, enforcing bundling is not a feasible policy. Because of $(g+G)_{\text {bund }}=t f+T[F-C]>t[f+F-C]$, it would conflict with the participation constraint (12). It comes even worse: Allowing unbundling is a feasible policy only if the migration of IP is not taxed. This follows from the comparison of aggregate tax payments:

$$
\begin{aligned}
(g+G)_{\text {unbund }}=t[f & +F-C]+X \\
& \leq t[f+F-C]=(g+G)_{\text {reloc }} \Leftrightarrow X \leq 0 .
\end{aligned}
$$

Proposition 6: If hosting of $\mathrm{R} \& \mathrm{D}$ is to be resilient against tax competition, the governing tax law has no other choice but to allow unbundling and to waive exit taxation. 


\section{One-book system}

Desai and Dharmapala (2011) recommend an international tax regime which requires transfer prices reported by MNEs to tax authorities to be consistent with the transfer prices used internally. The authors call such a transfer-pricing norm the performance related principle. The proposal's essence is presumably better reflected when speaking of a one-book system.

The appeal of the one-book system derives from the fact that it sustains internal efficiency when MNEs decentralize management. There must be a perfect internal market in which the sharing division demands the know-how which the developing division supplies at a price $P \equiv R_{i}^{\prime}=R_{e}^{\prime}$ which both divisions take as given. In equilibrium, the traded know-how is paid its marginal product at the internally efficient level, $P=f^{\prime}\left(K_{i}^{*}\right)$.

The caveat of the one-book system is that governments cannot enforce decentralized management. The option to reduce the tax bill gives centralization an advantage which MNEs will only trade off against the potential managerial costs of centralization. The great advantage of the two-book system is that it allows MNEs to minimize tax payments and to decide independently on the extent of decentralization in managerial organization.

In a model with rival costs of production, Nielsen (2014) shows that the switch from a twobook system to a one-book system does not remove the ability to manipulate tax payments; rather, it only moderates it. There are, however, additional drawbacks. The one-book system cannot guarantee resilience against tax competition nor inter-country equity. Much depends on the specific choice of parameters. This is easily demonstrated when focusing on the following scenario: Pricing is linear, $R \equiv P K$, withholding taxes are not levied, and the managerial cost of centralization increases quadraticly in the difference between the chosen transfer price and the marginal product of know-how, $Z=z\left(P-f^{\prime}\right)^{2} K / 2$. One may think of information asymmetries between the MNE's headquarter and the divisions impeding internal efficiency. If ownership rights are bundled in home, the MNE maximizes

$$
\pi+\Pi=(1-t)[f-P K]+(1-T)[F+P K-C]-z\left(P-f^{\prime}\right)^{2} K / 2
$$

in $P$ yielding $P_{b u}=f^{\prime}-(T-t) / z$. The optimal price is set below the efficient one as $T>t$ holds by assumption. If the MNE chooses to relocate $R \& D$, it will maximize

$$
\pi+\Pi=(1-t)[F+P K-C]+(1-T)[F-P K]-z\left(P-f^{\prime}\right)^{2} K / 2
$$


in $P$ yielding $P_{r e}=f^{\prime}+(T-t) / z$. One can easily verify the following equivalence:

$$
\begin{aligned}
& (g+G)_{\text {bund }}=t\left[f-P_{b u} K\right]+T\left[F+P_{b u}-C\right] \\
& \quad \leq t\left[f+P_{r e}-C\right]+T\left[F-P_{r e}\right]=(g+G)_{\text {reloc }} \Leftrightarrow 2 f^{\prime} K \leq C .
\end{aligned}
$$

Hence, it depends on $f^{\prime}, K$, and $C$ whether the MNE chooses to relocate or not. Host's tax base is

$$
b=f-P_{b u} K=f-f^{\prime} K+\frac{1}{z}(T-t) K .
$$

Strict concavity of $f$ implies $0<f-f^{\prime} K<f$. Eq. (17) reveals that inter-country equity is obtained only if the term with $z$ is sufficiently small, i.e., if the value of $z$ is large. This means that the managerial cost of centralization must be sufficiently high if tax planning is to sustain an equitable distribution of the tax base.

Proposition 7: A one-book system creates incentives to centralize management. Only if the managerial cost of centralization is sufficiently large, is inter-country equity obtained. Resilience against tax competition is not secured.

\section{Regulated profit splitting}

Following Shapley, an equal split of the income earned with imported know-how suggests itself as a benchmark of inter-country tax equity. The benchmark draws attention to profit splitting in a broader sense termed regulated profit splitting (RPS) in this paper. According to this proposal some fixed share $\sigma \in(0,1)$ of the licensee's profit determined before royalty payments is allocated to the licenser for purposes of taxation. Boundary values of $\sigma$ are excluded. The lower bound, $\sigma=0$, captures source taxation and the upper bound, $\sigma=1$, captures residence taxation. Inter-country equity in the sense of Shapley requires a value of $\sigma$ not lower than $1 / 2$ but lower than 1 .

The following three scenarios will be compared: (i) bundling, (ii) unbundling with exit taxation, and (iii) relocating $R \& D$. The following inequalities can be easily verified:

$$
(g+G)_{b u n d}=t(1-\sigma) f+T[F+\sigma f-C]
$$




$$
\begin{gathered}
\leq t[f+\sigma F-C]+T(1-\sigma) F=(g+G)_{\text {reloc }} \\
\Leftrightarrow \sigma(f+F) \leq C \Leftrightarrow \rho=(f+F-C) / C \leq(1-\sigma) / \sigma \\
(g+G)_{\text {bund }} \leq t[f+\sigma(F-C)]+T(1-\sigma)[F-C]+X=(g+G)_{\text {unbund }} \\
\Leftrightarrow(T-t) \sigma(f+F-C) \leq X
\end{gathered}
$$

These inequalities hold simultaneously if $\sigma$ is sufficiently small and if $X$ is sufficiently large. To give an example, set $X \equiv x T C$ and $\sigma$ subject to $1-x \leq \sigma \leq 1 /(1+\rho)$. Equations (18) and (19) simultaneously hold in this case. This means that resilience against tax competition and unbundling can be achieved in a regime with RPS if the splitting parameter and the exit tax are appropriately chosen. The choice of the exit tax falls into home's undivided competence. By contrast, the choice of $\sigma$ requires an international agreement. Two features should, however, facilitate the search for an agreement. First, inequality (18) is independent of tax rates. It's derivation only assumes $T>t$. Second, negotiations on $\sigma$ should not be too antagonistic. Although home's tax revenue increases in $\sigma$ as shown below, home will not be keen to drive up $\sigma$, as this tends to conflict with inequality (18). Clearly, a low value of $\sigma$ is in host's interest as host's tax revenue decreases in $\sigma$. For the benchmark of inter-country equity, $\sigma=1 / 2$, eq. (18) requires $\rho \leq 1$. Most investment projects will satisfy this constraint. This is so as $\rho$ has to be interpreted as an expected rate of return. The decision to relocate must be thought to be made ex ante, i.e., before the success of R\&D has been materialized.

Assuming bundling, the MNE determines optimal know-how $\bar{K}_{\sigma}$ by solving the first-order condition of profit maximization:

$$
(1-T)\left[f^{\prime}+F^{\prime}-C^{\prime}\right]=-(T-t)(1-\sigma) f^{\prime}
$$

Implicit differentiation reveals that optimal know-how decreases in $\sigma$ for $T>t$ :

$$
\frac{d}{d \sigma} \bar{K}_{\sigma}=\frac{(T-t) f^{\prime}}{D}<0
$$

where $D \equiv(1-T)\left[F^{\prime \prime}-C^{\prime \prime}\right]+(1-\tau) f^{\prime \prime}<0$ and where $\tau \equiv(1-\sigma) t+\sigma T$ is the weighted tax rate. For $\sigma=1$, eq. (20) implies that $F^{\prime}+f^{\prime}=C^{\prime}$. Residence taxation sustains internal efficiency, as all returns to $R \& D$ are taxed at the same rate as used for deducting costs. By contrast, optimal R\&D exceeds the internally efficient level, $\bar{K}_{\sigma}>K_{i}^{*}$, for $\sigma<1$ and $T>t$. As there is no connection between $(T-t)(1-\sigma) f^{\prime}$ and $(1-T) E^{\prime}$ the effective subsidizing 
of know-how can, however, be either too weak or too strong in terms of external efficiency. As mentioned before, $g=t(1-\sigma) f$ decreases in $\sigma$ and $G=T[F+\sigma f-C]$ increases in $\sigma$ :

$$
\begin{aligned}
& \frac{d}{d \sigma}[(1-\sigma) f]=-f+(1-\sigma) f^{\prime} \frac{d}{d \sigma} \bar{K}_{\sigma}<0, \\
& \frac{d}{d \sigma}[F+\sigma f-C]=f+\left[F^{\prime}+\sigma f^{\prime}-C^{\prime}\right] \frac{d}{d \sigma} \bar{K}_{\sigma}>0 .
\end{aligned}
$$

The bracketed expression on the right-hand side of eq. (22) is negative as can be shown when rearranging eq. (20):

$$
F^{\prime}+\sigma f^{\prime}-C^{\prime}=-(1-\sigma) \frac{1-t}{1-T} f^{\prime}<0 . .^{4}
$$

Proposition 8: By well-designed exit taxation and an appropriate choice of the splitting parameter, RPS can be made resilient against tax competition and unbundling. A low value of $\sigma$ serves the interest of home by securing resilience against tax competition. It even more serves the interest of host by boosting host's tax revenue. Inter-country equity is secured, and optimal R\&D exceeds the internally efficient level.

There is a noteworthy, technical connection between RPS and sales-based FA. This connection can be shown to exist when making the unrealistic assumption that the rate of return to $R \& D$ is constant across projects. A leviathan perspective suggests that international tax policy should maximize $(g+G)_{\text {bund }}$ subject to $(g+G)_{\text {bund }} \leq(g+G)_{\text {reloc }}$. As eq. (18) reveals, the solution would be $\rho=(1-\sigma) / \sigma$. It is easily verified that this equality holds if, and only if, the two tax bases are equal:

\footnotetext{
${ }^{4}$ Note that optimal know-how increases in $T, \frac{d}{d T} \bar{K}_{\sigma}=\frac{\left[F^{\prime}+\sigma f^{\prime}-C^{\prime}\right]}{D}>0$, while it decreases in $t, \frac{d}{d t} \bar{K}_{\sigma}=\frac{(1-\sigma) f^{\prime}}{D}<$ 0 . Income of host, $g$, is maximized at rate $t=-\frac{f}{f^{\prime} \frac{d}{d t} \bar{K}_{\sigma}}>0$ and income of home, $F+\sigma f-C+E$, is maximized at the rate $T$ equating $E^{\prime}$ and $(1-\sigma) \frac{1-t}{1-T} f^{\prime}$ when evaluated at $\bar{K}_{\sigma}=\bar{K}_{\sigma}(T, t)$. This is only mentioned without assuming that governments set income maximizing tax rates. Rather, tax rates are assumed to be exogenously fixed. If the opposite case were taken seriously, it would suggest MNE-specific tax rates. Such a suggestion is neither realistic nor reasonable.
} 


$$
B_{R P S}=F+\sigma f-C=\frac{F}{f+F}(f+F-C)=B_{\text {sales-based } F A} .
$$

One could think about combining RPS with crediting. ${ }^{5}$ In such a regime, the right of taxing profit earned with IP would principally be allocated to the country in which IP is held. The profit earned with licensed know-how in another country would, however, be split, and the tax paid by the licensee in his country of residence would be credited against the licenser's tax liability. In the scenario in which the licenser is the developing division, the MNE pays taxes $f=(1-\sigma) f$ to host and $G=T[f+F-C]-g$ to home. It is obvious that the regime with crediting is not resilient against tax competition. The MNE could reduce its tax bill by relocating to the low-tax country.

\section{Implementing regulated profit splitting}

If RPS is to be a realistic policy option, it has to offer convincing solutions in scenarios which are not as simple as the one which has been analyzed above. This section is devoted to a discussion of less simple scenarios. The first one assumes that know-how is developed in $n>1$ home countries and that profit $f$ is generated in just one host country. As mentioned in section 3.2, the Shapley value suggests a tax base $b_{n}$ for host which is positive but not larger than $f /(n+1)$. The fact that the number of cooperating countries determines the bound suggests treating the division only sharing know-how as an entity held jointly by all the divisions supplying know-how. This is a bit like unitary taxation. It does not, however, go as far as FA. Only the sharing division's profit contribution (determined before royalty payments) is divided. The developing divisions' profit contributions are not.

This clarifying remark draws attention to questions surrounding the determination of taxable income. A particular issue is raised when licensed know-how is not the sole source of profit. To be more specific, let us assume that output, $f=f(l)$, is a natural resource which is extracted at an increasing cost, $c(l)$. If external know-how, $K$, helps to reduce the cost, $c(l)=c(l, K)$, of extraction, splitting the full profit, $\pi(K) \equiv \max [f(l)-c(l, K) l]$, does not seem appropriate. The share of profit attributable to external know-how is $\pi(K)-\pi(0)$ and not more. The remaining share of profit, $\pi(0)$, is attributable to the scarcity of the resource which is ideally determined by applying arm's length pricing methods. In practice, the separation is likely to raise difficulties. In theory, things are, however, clear. The rule should

\footnotetext{
${ }^{5}$ This suggestion has been made by Ulrich Schreiber in a private communication.
} 
be that profit earned with a rival factor like a natural resource, capital or land is allocated to the country bearing the factor cost and the determination should rely on arm's length pricing methods. Only the residual profit which cannot be explained by the use of rival factors can be reasonably attributed to know-how and, thus, subjected to RPS.

\section{Summary and concluding remarks}

MNEs are established with the aim of exploiting accumulated know-how (Dunning, 1979). Know-how is a non-rival factor of production, the importance of which has dramatically gone up with the rise of the new economy. Its digital materialization is software. The increasing use of preferential tax provisions for $R \& D$ demonstrates that governments have begun to recognize the strategic importance of know-how for prosperity and growth. Tax competition for the hosting of R\&D activity and ownership rights has intensified as is indicated by the increasing spread of patent-box regimes (Alstadsaeter et al., 2015; Evers et al., 2015). This development has symptoms of a race to the bottom with unclear welfare implications.

This is the background against which this paper focuses on the taxation of non-rival factors of production. It is argued that a viable international order for the taxation of MNEs should, in addition to enhancing efficiency, meet the following three desiderata: (i) resilience against tax competition, (ii) inter-country equity, and (iii) incentive compatibility in information exchange. The governing tax law suffers from insufficient resilience against tax competition. Resilience is only secured if unbundling is tolerated (Proposition 6). However, allowing unbundling comes at the cost of inter-country inequity. A withholding tax with limited crediting does not improve the situation (Proposition 5).

It has been shown that the most prominent proposals for reforming international taxation would not bring any decisive progress. The Destination-Based Cash Flow Tax (DBCFT) is not resilient against tax competition, and it fails to convince with respect to inter-country equity (Proposition 2). Unitary taxation with formulary apportionment has the problem of not being incentive compatible in information exchange. The Massachusetts formula, additionally, suffers by lacking resilience against tax competition (Proposition 3). Switching from the two-book reporting system to a one-book system would produce ambiguous effects. Only if managerial costs of centralization are sufficiently large, is inter-country equity 
secured. Resilience against tax competition can only be shown to hold in special scenarios (Proposition 7).

This paper makes a case for regulated profit splitting (RPS). Under such a regime, the profit earned with licensed know-how is split between the licenser and the licensee for the purpose of taxation. The assumption is that the splitting ratio is internationally agreed. It is shown that RPS meets all desiderata. This means that it secures inter-country equity and incentive compatibility in information exchange. By well-designed exit taxation and an appropriately chosen splitting parameter, RPS can also be made resilient against tax competition and unbundling (Proposition 8). One must only assume that there is some bound which the expected rate of return to $R \& D$ does not exceed. It is argued that international negotiations regarding the choice of the splitting parameter should not be overly antagonistic. An equal split is a highly suggestive benchmark.

It has to be stressed that this paper pleads for splitting the profit earned with non-rival factors of production. Any profit earned with a rival factor of production would ideally be determined by applying arm's length pricing and not split for the purpose of taxation. The only object of splitting is residual profit.

One cannot finish such an analysis without stressing its theoretical nature. The results obtained rely on a whole array of simplifying assumptions, thus, suggesting caution when making policy recommendations. The following sets of simplifying assumptions deserve to be stressed more than others. The first one relates to the paper's model of an MNE. The production of goods with input choices of capital and labor has not been modeled. The sole focus has been on the development of know-how. The cost of R\&D has been specified in an ad-hoc fashion as has been the managerial cost of management. The second set of simplifying assumptions relates to taxation. The cost of $R \& D$ is assumed to be tax deductible. In practice, complete deductibility may not be provided. Typical reasons are incomplete loss offsetting and tax disadvantaged equity-based remuneration schemes that are used more and more to incentivize highly skilled employees (Griffith and Miller, 2014). Taxes have been modeled to only differ internationally with respect to rates. Complications raised by hybrid mismatch arrangements have been ignored although the OECD' Action Plan on BEPS (2013) specifically addresses them. Preferential tax provisions for R\&D such as patent boxes and cost subsidies which are widely granted in practice have not been modeled. For details of the practice see Evers et al., 2015. Finally, the method by which all the tax regimes have been 
compared in this paper is only partially analytical. Key variables have not been endogenized. Future research will have to explore the implications of removing all such simplifications.

\section{References}

Alstadsaeter, Annette; Barrios, Salvador; Nicodème, Gaëtan; Skonieczna, Agnieszka M.; Vezzani, Antonio (2015): Patent Boxes Design, Patents Location and Local R\&D, European Commission, Working Paper N. 57.

Altshuler, Rosanne; Grubert, Harry (2010): Formula Apportionment: Is it better than the Current System and are There Better Alternatives? National Tax Journal 63, 1145-1184.

Auerbach, Alan J.; Devereux, Michael P. (2015): Cash-Flow Taxes in an International Setting, University of California Berkley and Oxford University, Discussion Paper.

Auerbach, Alan J.; Devereux, Michael P.; Keen, Michael; Vella, John (2017): DestinationBased Cash Flow Taxation, University of Oxford, Working Paper 17/01.

Avi-Yonah, Reuven S. (1993): Slicing the Shadow: A Proposal for Updating U.S. International Taxation, University of Michigan, Tax Notes 58, 1511-1515.

Avi-Yonah, Reuven S.; Clausing, Kimberly A.; Durst, Michael C. (2009): Allocating Business Profits for Tax Purposes: A Proposal to Adopt a Formulary Profit Split, Florida Tax Review 9, 497-553.

Beer, Sebastian; Loeprick, Jan (2015): Profit Shifting: Drivers of Transfer (Mis)Pricing and the Potential of Countermeasures, International Tax and Public Finance 22, 426-451.

Boos, Monica (2003): International Transfer Pricing: The Valuation of Intangible Assets, The Hague.

Bräutigam, Rainer; Spengel, Christoph; Streif, Frank (2015): Decline of CFC Rules and Rise of IP Boxes: How the ECJ Affects Tax Competition and Economic Distortions in Europe, ZEW Discussion Paper No. 15-055.

Commission Expert Group on Taxation of the Digital Economy (2014), Final Report, 28 May, Brussels. 
Desai, Mihir A.; Dharmapala, Dhammika (2011): An Alternative Transfer Pricing Norm, Working Paper, Harvard Business School and University of Illinois at Urbana-Champaign.

Devereux, Michael P. (2004): Debating Proposed Reforms of the Taxation of Corporate Income in the European Union, International Tax and Public Finance, 71-89.

Dharmapala, Dhammika (2014): What Do We Know about Base Erosion and Profit Splitting? A review of the Empirical Literature, Fiscal Studies 35, 421-448.

Dischinger, Matthias; Riedel, Nadine (2011): Corporate Taxes, Profit Shifting and the Location of Intangibles within Multinational Firms, Journal of Public Economics 95, 691707.

Dudar, Olena; Spengel, Christoph; Voget, Johannes (2015): The Impact of Taxes on Bilateral Royalty Flows, ZEW Discussion Paper No. 15-052.

Dunning, John H. (1979): Toward an Eclectic Theory of International Production: Some Empirical Tests, Journal of International Business Studies 11, 9-31.

Eggert, Wolfgang; Schjedelrup, Guttorm (2003): Symmetric Tax Competition under Formula Apportionment, Journal of Public Economic Theory 5, 439-446.

Eichner, Thomas; Runkel, Marco (2008): Why the European Union Should Adopt Formula Apportionment with a Sales Factor, Scandinavian Journal of Economics 110, 567-589.

Enders, Dieter; Spengel, Christoph (2015): International Company Taxation and Tax Planning, eds., Kluwer Law International.

European Commission (2011): Proposal for a Council Directive on a Common Consolidated Corporate Tax Base (CCCTB), Brussels, COM(2011) 121/4.

European Commission (2015): A Fair and Efficient Corporate Tax System in the European Union: 5 Key Areas for Action, Brussels, COM(2015) 302 final.

Evers, Lisa; Spengel, Christoph (2014): Effective Tax Rates under IP Tax Planning, ZEW Discussion Paper No. 14-111. 
Evers, Lisa; Miller, Helen; Spengel, Christoph (2015): Intellectual Property Box Regimes: Effective Tax Rates and Tax Policy Considerations, International Tax and Public Finance 22, 502-330.

Fuest, Clemens (2008): The European Commission's Proposal for a Common Consolidated Corporate Tax Base, Oxford Review of Economic Policy 24, 720-739.

Fuest, Clemens; Spengel, Christoph; Finke, Katharina; Heckemeyer, Jost; Nusser, Hannah (2013): Profit Shifting and 'Aggressive' Tax Planning by Multinational Firms: Issues and Options for Reform, World Tax Journal 5, 307-324.

Goldscheider, Robert; Jarosz, John; Mulhern, Carla (2005): Use of the 25\% rule in valuing intellectual property, in: Intellectual Property: Valuation, Exploitation, and Infringement Damages, Smith, Gordon V.; Parr, Russell L., eds., John Wiley and Sons, 410-426.

Gonnet, Sébastian; Fris, Pim (2007): Contribution Analyses under the Profit Split Method, International Tax Review.

Gresik, Thomas A. (2010): Formula Apportionment vs. Separate Accounting: A Private Information Perspective, European Economic Review 54, 113-149.

Griffith, Rachel; Miller, Helen (2014): Taxable Corporate Profits, Fiscal Studies 35, 535-557.

Griffith, Rachel; Miller, Helen; O`Connell, Martin (2014): Ownership of Intellectual Property and Corporate Taxation, Journal of Public Economics 112, 12-23.

Grubert, Harry (2003): Intangible Income, Intercompany Transactions, Income Shifting, and the Choice of Location, National Tax Journal 56, 221-242.

Haufler, Andreas; Mardan, Mohammed (2014): Cross-Border Loss Offset Can Fuel Tax Competition, Journal of Economic Behavior \& Organization 106, 42-61.

Heckemeyer, Jost H.; Overesch, Michael (2013): Multinationals’ Profit Response to Tax Differentials: Effect Size and Shifting Channels, ZEW Discussion Paper 13-045.

Hiemann, Moritz; Reichelstein, Stefan (2012): Transfer Pricing in Multinational Corporations: An Integrated Management and Tax Perspective, in: Fundamentals in International Transfer Pricing in Law and Economics, Schön, Wolfgang; Konrad, Kai A., eds., MPIS Studies in Tax Law and Public Finance 1, Berlin and Heidelberg, 3-18. 
Johnson, Nicole Bastian (2006): Divisional Performance Measurement and Transfer Pricing for Intangible Assets, Review of Accounting Studies 11, 339-365.

Karkinsky, Tom; Riedel, Nadine (2012): Corporate Taxation and the Choice of Patent Location within Multinational Firms, Journal of International Economics 88, 176-185.

Knoppe, Helmut (1972): Die Besteuerung der Lizenz- und Know-how-Verträge, Berlin.

McLure, Charles E. (1980): The State Corporate Income Tax: Lambs in Wolves' Clothing, in: The Economics of Taxation, Aaron, Henry J.; Boskin, Michael J., eds., Brookings Institution, Washington DC, 327-336.

Luckhaupt, Hagen; Overesch, Michael; Schreiber, Ulrich (2012): The OECD Approach to Transfer Pricing: A Critical Assessment and Proposal, in: Fundamentals in International Transfer Pricing in Law and Economics, Schön, Wolfgang; Konrad, Kai A., eds., MPIS Studies in Tax Law and Public Finance 1, Berlin and Heidelberg, 91-121.

Mutti, John; Grubert, Harry (2009): The Effect of Taxes on Royalties and the Migration of Intangible Assets Abroad, in: International Trade in Services and Intangibles in the Era of Globalization, Reinsdorf, Marshall; Slaughter, Matthew J., eds., University of Chicago Press, 111-137.

Nielsen, Soren Bo (2014): Transfer Pricing: Roles and Regimes, Journal of World Economy/Revista de Economia Mundial 37, 103-122.

OECD (2013): Action Plan on Base Erosion and Profit Shifting, Paris.

Parr, Russell L. (2013): Intellectual Property: Valuation, Exploitation and Infringement Damages, Cumulative Supplement, 11th Edition.

Pethig, Rüdiger; Wagener, Andreas (2007): Profit Tax Competition and Formula Apportionment, International Tax and Public Finance 14, 631-655.

Riedel, Nadine (2014): Quantifying International Tax Avoidance: A Review of the Academic Literature, Paper Prepared for the European Tax Policy Forum, Ruhr-University of Bochum, mimeo.

Russo, Raffaele (2007): Fundamentals of International Tax Planning, IBFD, Amsterdam. 
Shapley, Lloyd S. (1967): The "Value of the Game" as a Tool in Theoretical Economics, RAND RM P-3658.

Vögele, Alexander; Gonnet, Sébastien; Gottschling, Bastian (2008); Transfer Prices Determined by Game Theory: 2 - Application to IP, Tax Planning Transfer Pricing International Journal (BNA), 11/08.

Wellisch, Dietmar (2004): Taxation under Formula Apportionment - Tax Competition, Tax Incidence, and the Choice of Apportionment Factors, Finanzarchiv 60, 24-41. 